
3 Research Square
Preprints are preliminary reports that have not undergone peer review.
They should not be considered conclusive, used to inform clinical practice,
or referenced by the media as validated information.

\title{
The Effect of Functional Mandibular Advancement for Adolecent Patients with Skeletal Class $₫$ Malocclusion on the TMJ--a Systematic Review and Meta- Analysis
}

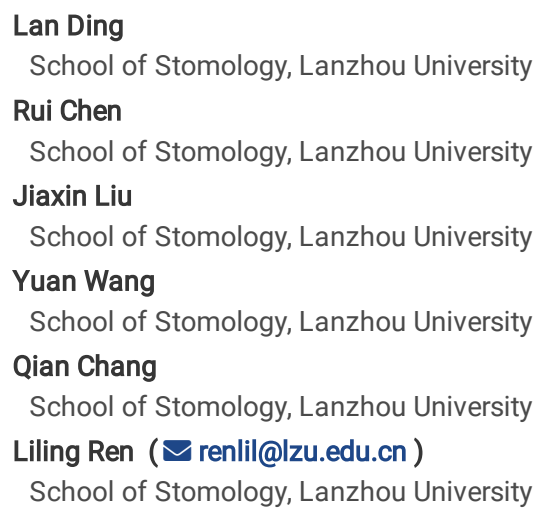




\section{Abstract}

Objectives: This study aimed to assess whether functional mandibular advancement will induce or aggravate temporomandibular joint disorders.

Methods: All searched databases, including PubMed, Web of Science, EMBASE, Cochrane Central Register of Controlled Trails were searched. Gray literature and unpublished literature was also searched. Randomized controlled trails directly observe the condition of patients' TMJ after finishing treatment will be considered to include in our study. Cochrane Collaboration risk of bias tool was used to assess the quality of included studies according to the established inclusion criteria.

Result:Finally 13 researches were statistically pooled in meta-analysis. The number of samples under investigated among primary studies was 285 individuals ,there were 142 patients who developed temporomandibular symptoms during or after treatment. But all the subjective symptoms disappeared during followup time. The statistical outcomes proved that patients recieved FMA didn't show more tendency to develop temporomandibular symptoms $\left[I^{2}=25 \%\right.$, OR=0.39, $95 \% \mathrm{Cl}(0.22,0.68), \mathrm{p}=0.001]$.

Conclusion: (1) TMJ symptoms may occur during the functional oral appliance wearing, but the symptoms will release or disappear during follow-up period. (2) Less convinced evidence indicate that slightly previous TMD will be improved after treatment. (3) There is TMJ disc anterior displacement observed during treatment, but most of them will return to the normal position later. (4) Moderate evidence support that FMA will not induce or aggravate TMD.

\section{Introduction}

Skeletal class $₫$ malocclusion is regarded as a common disease among people[1-4], and its mechanism is either the overgrowing of maxillary, or the deficient of the mandibular[5].For the second type, functional mandibular advancement has become an effective treatment for skeletal class $\nabla$ malocclusion[6-8], it aimed to stimulate mandibular growth by forward positioning of mandible, which is available to correct such skeletal disharmony, and to improve facial profile[9]. However, forward mandibular positioning will make the disc at a more advanced position, which may rise TMD symptoms .

Although many researches in animals have proved there was no TMD symptom after functional mandibular advancement[7, 10], controversy still exists in human because of the adaption mechanism of the TMJ to mandibular advancement during treatment[11, 12]. Some researchers hold the opinion that mandibular advancement will have positive influence on TMJ reconstruction, which can help modifying more proper condyle-glenoid fossa relationship[13]'but on the contrary, others think that mandibular advancement may be the cause of TMDs, since it breaks the balance of occlusion[14-16]. However, above researches were all based on the clinical trials, the sample is not enoughl to convince, also the potential bias from researchers selecting cases may affect their results. There is not enough evidence of existed literature regarding the effect of functional mandibular advancement on TMJ.

Some previous systematic review and meta-analysis published by Kurt Popowich[17] and Laura Ivorra-Carbonell[18] analyzed the morphology of TMJs after functional mandibular advancement, both of their researches found that the condyle was in a more advanced position, with remodelling of condyle and gleniod fossa; and no significant adverse effect was detected. But the results were inconclusive. Their evaluation of such problem was qualltative, which made the results less convinced. This systematic review and meta-analysis was undertaken to answer whether functional mandibular advancement would have adverse effect on TMJs in adolecence in quantitative standard, since no quantitative assessment was undertaken before.

\section{Objectives}

This systematic review and meta-analysis was aimed to evaluate the risk of develpoing TMD after functional mandibular advancement in adolescence, and deciding whether to use such proposal to treat class $₫$ patients.

\section{Materials And Methods}

\section{Protocol and registration}

The protocol of this systematic review was developed and registered prospectively in PROSPERO (www.crd.york.ac.uk/prospero, CRD42020157906). The present review was performed following the Cochrane Handbook for Systematic Reviews of Interventions[19] and is reported as suggested by PRISMA[20]

\section{Eligibility criteria}

The following selection criteria were applied for this study.

1. Study design: randomized and controlled clinical trials, along with systematic review, which considered the TMJ condition of patients after functional mandibular advancement with the observation of a relatively long follow-up time(at least 1 year).

2. Participants: adolescent patients who had received functional mandibular advancement.

3. Interventions: functional mandibular advancement devices were used to improve profile and class $₫$ malocclusion.

4. Inclusion and exclusion criteria: Inclusion critera: a. All control trails about the influence on TMJ caused by functional mandibular advancement; b. Patients with good compliance till the end of study are of over $80 \%$ of the case number; c. Patients who didn't receive orthodontic treatment ,orthognathic surgery or 
TMJ treatment before; $d$. The patients' age should be under 16; e. The studies are considered to be high quality or medium quality. Exclusion Criteria: a. Repeated researches; b. Studies which didn't have control trails or before and after comparison; c. The patients whose age is over 16; d. The studies are considered to be low quality by the criteria ordered by cochrane handbook for systematic reviews of interventions.

5. Outcome measures: we set 5 main indicators to assess the outcomes, they were TMJ morphology before and after treatment, reported muscle disorders, position of TMJ disc before and after treatment, reported TMJ noises, reported Oral-facialpain and reported TMJ pain.

\section{Information sources, search strategy, and study selection}

International databases were used to find published articles from the opening of the database to August 2021. All searched databases, including PubMed, Web of Science, EMBASE, Cochrane Central Register of Controlled Trails were thoroughly searched using keywords: mandibular advancement, mandibular forward positioning, functional mandibular advancement, Herbst appliance, activator appliance, bionator appliance, twin-block appliance, Fränkel appliance, Forsus appliance, temporomandibular joint, temporomandibular joint disease, craniofacial pain, condylar resorption, class $₫$ malocclusion, orthodontics, randomized clinical trial, controlled clinical trail, double-blinded method and single-blinded method.(searching strategies are supported in Supplementary Material 1). Also, gray literature was sought by hand search, and contacting the author to ask for the original text of meetings and conference abstract should be required.

Search evaluation and the assessment of risk of bias were made by 2 researches independently, and if there exists any dispute, the evaluation should be reevaluated by the third researcher. Original articles, case reports, case series, meetings and conference abstracts which are published in English are considered in this study. We also search for bibliographic survey to enhance the sensitivity and to select more articles. Unpublished literature was searched electronically in ClinicalTrials.gov (www.clinicaltrials.gov) and the National Research Register (www.controlled-trials.com).

Full text or brief of all studies, reports, meeting or conference abstracts resulted from advanced search were extracted. After detailed screening the topic, abstract, and the full text, and removing the duplicates, so that the unrelated studies could be excluded and the related ones could be selected. The articles considered for this study including randomized controlled trails and systematic reviews.

\section{Data items and collection}

For each study, data were extracted based on topic, published year, type of study, total sample size, the ratio of gender, average age of patients, total amount of advancement, follow-up time, examination after finishing the treatment, outcome and result synthesis. All the data were performed in Table 1. 
Table 1

Characteristic of all included studies

\begin{tabular}{|c|c|c|c|c|c|c|c|c|c|c|}
\hline $\begin{array}{l}\text { Study } \\
\text { ID(country) }\end{array}$ & $\begin{array}{l}\text { Type } \\
\text { of } \\
\text { study }\end{array}$ & $\begin{array}{l}\text { Sample } \\
\text { size }\end{array}$ & Gender(M/F) & $\begin{array}{l}\text { Average } \\
\text { age } \\
\text { (year) }\end{array}$ & $\begin{array}{l}\text { Total amount } \\
\text { of } \\
\text { advancement }\end{array}$ & $\begin{array}{l}\text { Treatment } \\
\text { period }\end{array}$ & $\begin{array}{l}\text { Follow- } \\
\text { up } \\
\text { time }\end{array}$ & $\begin{array}{l}\text { Examination on } \\
\text { TMJ }\end{array}$ & Outcome & Result synthesis \\
\hline $\begin{array}{l}\text { Aidar et al. } \\
2009\end{array}$ & RCT & 32 & $16 / 16$ & $12.8 y$ & $<6 \mathrm{~mm}$ & $12 m$ & $12 m$ & MRI & a & \\
\hline Brazil & & & & & & & & & & $\begin{array}{l}\text { the } 64 \text { TMJs, afte } \\
\text { follow-up, the dis } \\
\text { had returned to } \\
\text { normal }\end{array}$ \\
\hline
\end{tabular}

limits. In 22 TMJ:

(34.37\%), no

changes were

observed after

follow-up.

\begin{tabular}{|c|c|c|c|c|c|c|c|c|c|c|}
\hline $\begin{array}{l}\text { Gabriela } \\
\text { Modesti- } \\
\text { Vedolin et } \\
\text { al. } 2018 \\
\text { Brazil }\end{array}$ & RCT & 18 & $10 / 8$ & $8.4 y$ & $<6 \mathrm{~mm}$ & $2 m$ & $2 m$ & $\begin{array}{l}\text { TMJ } \\
\text { examination+CBCT }\end{array}$ & $b$ & $\begin{array}{l}82.6 \% \text { to } 88.9 \% \text { o } \\
\text { the patients didn' } \\
\text { report the } \\
\text { discomfort of } \\
\text { TMJs, and no dis } \\
\text { displacement wa } \\
\text { observed. }\end{array}$ \\
\hline
\end{tabular}

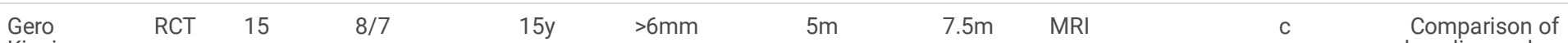

et al. 2006

Germany

treatment finding

re-

vealed that none the joints exhibit $\epsilon$

a treatment-

induced

deterioration in th disc-condyle

relationship, whil the relation-

ship improved in five joints.

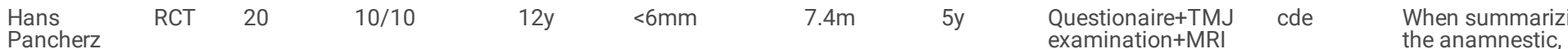

Pancherz

$10 / 10$

et al. 1998

the anamnestic,

clinical and

magnetic

Germany

findings five

subjects $(25 \%)$

exhibited modera

to severe signs of

temporomandibu

disorders ranging

from partial to

total disk

displacement or

"deviation in forn

of the condyle.

Another three

subjects $(15 \%)$

showed mild

symptoms of temporomandibu disorders with

either small

condylar

displacement or subclinical soft

tissue

lesion.

\begin{tabular}{|c|c|c|c|c|c|c|c|c|c|c|}
\hline $\begin{array}{l}\text { Ken } \\
\text { Hansen et } \\
\text { al. } 1990 \\
\text { Germany }\end{array}$ & RCT & 38 & $19 / 19$ & $12.4 y$ & $<6 \mathrm{~mm}$ & $6 m$ & $7.5 y$ & $\begin{array}{l}\text { Questionaire+TMJ } \\
\text { examination+CBCT }\end{array}$ & df & $\begin{array}{l}\text { No tenderness or } \\
\text { lateral or posteric } \\
\text { palpation of the } \\
\text { TMJ was recorde } \\
\text { in any of the } \\
\text { subjects. }\end{array}$ \\
\hline $\begin{array}{l}\text { Niko C. } \\
\text { Bock et al. }\end{array}$ & RCT & 72 & $32 / 40$ & $13.6 y$ & $>6 \mathrm{~mm}$ & $1.8 \mathrm{y}$ & $18.3 y$ & TMJ examination & bdf & $\begin{array}{l}79-91 \% \text { of the } \\
\text { patients were fret }\end{array}$ \\
\hline
\end{tabular}




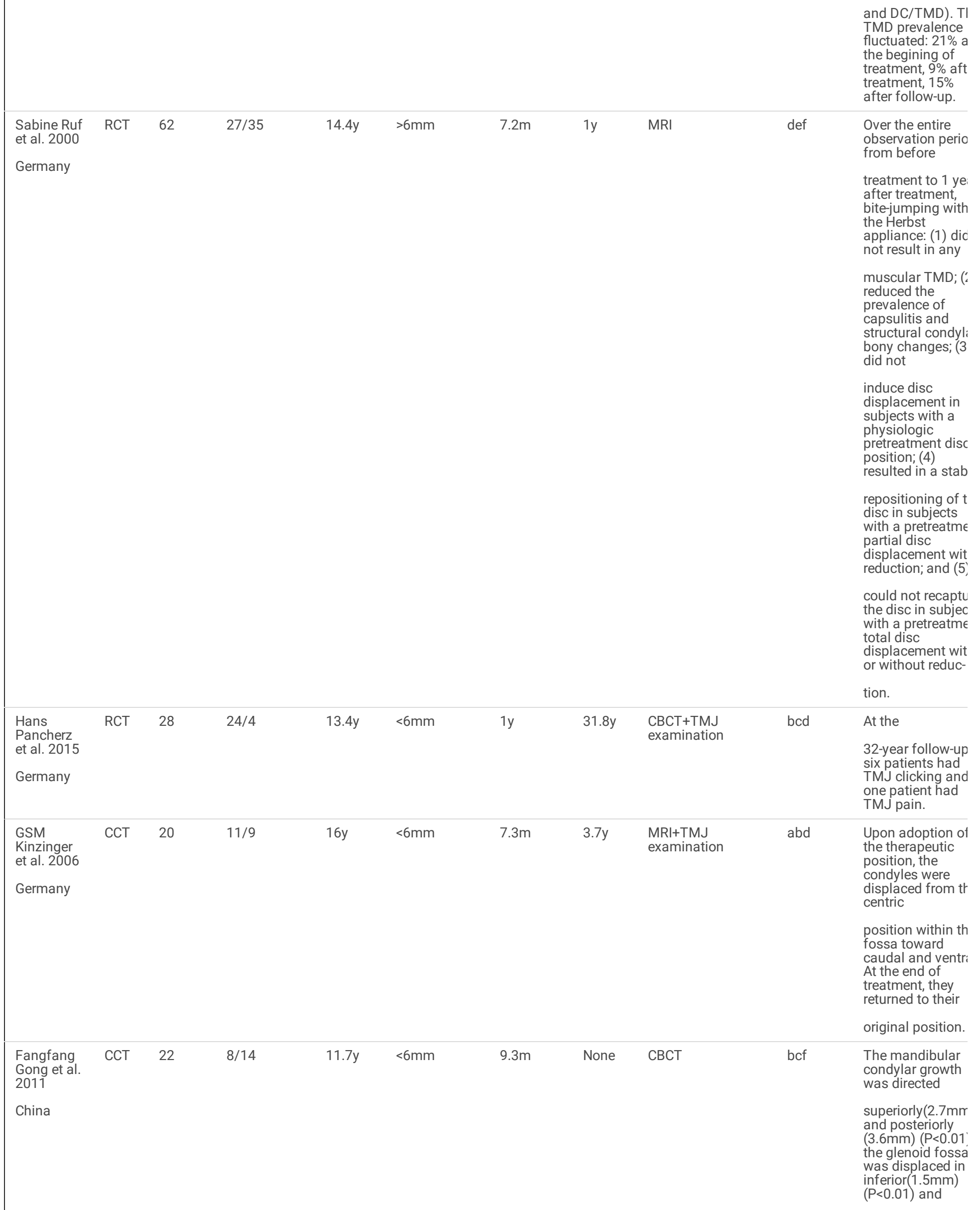




\section{Risk of bias/quality assessment in individual studies}

After selection of the studies in terms of the topic, abstract and design of the experiment, to assess the quality of the selected studies, Cochrane Collaboration risk of bias tool[21] was used to assess the quality of every study. Seven criteria were analyzed to grade the risk of bias inherent in each study, including random sequence generation, allocation concealment, blingding of participants and personnel, blinding of outcome assessment, incomplete outcome data, selective reporting and other potential source of bias. Studies with at least 1 criterion of high risk would be regarded as having a high risk of bias overall, and excluded from meta-analysis. According to the guide of Cochrane Handbook, systematic reviews are considered as high quality evidence and capable of including in systematic review.

\section{Summary measures and approach to synthesis}

Heterogeneity of the included studies was gauged by assessing the treatment protocol-follow-up year, gender ratio, publish year. Statistical heterogeneity was assessed by a forest plot in conjunction with $95 \%$ confidence intervals. P value below 0.1 meant significant heterogeneity. Index among studies was determined, applying $\mathrm{Z}$ test and I-squared, according to heterogeneity results, random or fixed model was used for estimation. The results for developing TMD were expressed as odds ratios(OR).

\section{Risk of bias across studies}

Funnel plot was drawn to identify publication bias, showed that the included studies had little publish bias.

\section{Additional analyses}

Sensitivity analyses were pooled to deal with studies with higher risk of bias, publication bias, and other potential sources of heterogeneity including follow-up time, publish year, gender ratio, treatment period and total amount of advancement in included studies would be assessed by subgroup analysis. Metaanalyses, sensitivity analyses and subgroup analyses were undertaken using Revman Ver 5.3 software.

\section{Result}

\section{Study selection and characteristics}

A sensitive search including 852 articles was found out. After reading the topic and abstract, 19 studies were selected in this study. And according to the exclusion criteria, 4 articles were excluded, so that 15 articles were included in this study finally. The flow of study selection is performed in PRISMA flow diagram(Supplementary Material 2).

PRISMA flow diagram of article retrieval

\section{Risk of bias within studies}

Seven criteria were pooled to analyze the inherent risk of bias of each included study, including random sequence generation, allocation concealment, blinding of participants and personnel, blinding of outcome assessment, incomplete outcome data, selective reporting, and other potential sources of bias. The results of quality assessment is showed in Fig 1. And an overview of author's judgments concerning all aspects of risk of bias is presented in Fig 2. Additionally, all included studies declared that there was no selective reporting of results in their studies. Considering all the patients should be infromed the orthodontic treatment plan, all authors stated in the literature that there was no attempt to blind the participants, but all the patients were not informed of others' treatment plan. In particular, our included articles mentioned blinding of all assessors.

Therefore, overall, 2 studies were deemed as low quality and they were not eligible for meta-analysis, other 8 studies were eligible to be pooled in metaanalysis. According to Cochrane Handbook, systematic review is considered to offer strong evidence, so 5 systematic reviews were also included, and the 


\section{Results of individual studies, meta-analysis, and additional analyses}

\section{Results of meta-analysis}

Revman Ver5.3 software was utilized to analyse data. Sensitivity analysis was also undertaken to determine effective studies in terms of heterogeneity.

Funnel plot was performed to assess publication bias(Fig 3), and the results showed that there was little publish bias among studies.

In this meta-analysis, we used OR as a statistical indicator, and the result showed in Fig 4 that the degree of heterogeneity is significant. [ ${ }^{2}=46 \%, \mathrm{OR}=0.47$, $95 \% \mathrm{Cl}(0.25,0.88), \mathrm{P}=0.02$ ] So that the random effects model was used to analyze the data. Meta-analysis performed that compared with pre-treatment, patients who received the intervention of functional mandibular advancement were less likely to have more serious TMD or attain new TMJ symptoms, and the consequence had statistical significance $\left({ }^{\star} \mathrm{P}<0.01\right)$.

Sensitivity analysis to examine role of each primary study in heterogeneity showed that research done by Hans Pancherz 1998 had the most effect on heterogeneity, and heterogenity decreased evidently after removing this study. $\left[I^{2}=25 \%, 0 R=0.39,95 \% \mathrm{Cl}(0.22,0.68), p=0.001\right]$. The result was performed in Fig 5 .

\section{Results of included systematic reviews}

After electronic searching, finally 5 systematic reviews were included in this study because they were directly related to the review topic and met the selection criteria. The synthesis of results and conclusions was demonstrated in Table 2 . And the results of these studies would be assessed in the following 3 aspects.

\section{Table 2}

The synthesis of results and conclusions of included systematic reviews

\begin{tabular}{|c|c|c|}
\hline Study ID & Country & Results/Conclusion \\
\hline Kurt Popowich et al. 2002 & Canada & $\begin{array}{l}\text { The MRI } \\
\text { studies did not provide conclusive evidence of osseous remodeling or condyle position change. The } \\
\text { tomography study demonstrated minor condyle position change. Methodological deficiencies prevented } \\
\text { major conclusions regarding disc position. }\end{array}$ \\
\hline $\begin{array}{l}\text { Laura Ivorra-Carbonell et al. } \\
2016\end{array}$ & Spain & $\begin{array}{l}\text { After treatment with functional appliances, the condyle was found to be in a more advanced position, } \\
\text { with remodelling of the condyle and adaptation of the morphology of the glenoid fossa. No significant } \\
\text { adverse } \\
\text { effects on the TMJ were observed in healthy patients and the appliances could improve joints that initially } \\
\text { presen- } \\
\text { ted forward dislocation of the disk. }\end{array}$ \\
\hline $\begin{array}{l}\text { Lucas Garcia Santana et al. } \\
2020\end{array}$ & Brazil & $\begin{array}{l}\text { Low to very low certainty of evidence } \\
\text { indicated that incremental mandibular advancement resulted in greater gains in } \\
\text { mandibular length }(M D=0.89[0.38,1.34], p=0.0005) \text {, anterior mandibular displacement } \\
(M D=0.73[0.40,1.06], p<0.001) \text { and } S N B \text { angle }(M D=0.44[0.02,0.85], p<0.04) \text {. }\end{array}$ \\
\hline $\begin{array}{l}\text { Karma Shiba Kyburz et al. } \\
2019\end{array}$ & Switzerland & $\begin{array}{l}\text { Currently existing evidence from controlled clinical studies on humans indicates that functional } \\
\text { appliance treatment is associated with positional and skeletal alterations of the temporomandibular joint } \\
\text { in } \\
\text { the short term compared to untreated controls. }\end{array}$ \\
\hline Xinqi Huang et al. 2016 & China & $\begin{array}{l}\text { The condylar position showed no changes after Herbst treatment. The con- } \\
\text { dylar posterior space after Twin-block treatment averagely increased by } 0.31 \mathrm{~mm}(\mathrm{P}<0.00001) \text {, whereas the } \\
\text { condylar anterior } \\
\text { space averagely reduced by } 0.32 \mathrm{~mm}(\mathrm{P}<0.00001) \text {. Twin-block appliance enables forward movement of the } \\
\text { condylar position. }\end{array}$ \\
\hline
\end{tabular}

\section{Temporommandibular joint symptoms}


Few cases in the included studies reported temporomandibular joint symptoms(32 of 962, 3.3\%) during treatment time, but these temporary symptoms disappeared during follow-up time. The reported symptoms included TMJ noises, TMJ pain and oral facial pain, but no TMJ dysfunction.

\section{Condyle and glenoid fossa remodelling}

In the studies of Popowich K[22], Ivorra-Carbonell L[23], Santana LG[24] and Kyburz KS[25], treated samples with permanent teeth were asked to take MRI before and after the removal of appliance to measure the mophology of TMJ region. Compared with pretreatment condition,both condyle and glenoid fossa remodelling was visually inspected through MRI, also an area of increased signal intensity in the posterosuperior region of the condyle was reported in the TMJs. Only 17 cases(1.8\%) reported "osteoarthritic changes or deviations in condyle form" after treatment, but none of the samples reported TMJ dysfunction, either.

\section{Condylar and TMJ disc position}

Xinqi Huang[26] stated in their study that after the treatment of twin-block appliance, the condylar posterior space increased whereas the condylar anterior

space reduced. But they revealed that no significant change of both anterior and posterior space of condylar was observed after the treatment of Herbst appliance. Otherwise, Kurt Popowich[17], Santana LG[24] and Kyburz KS[25] all measured TMJ disc on MRI, they found that at the end of treatment, totally 47 patients(4.9\%) had disc displacement, but during the follow-up year for about 1 year, the disc all had normal position. To conclude, after functional mandibular advancement enables forward movement of the condylar position, and the TMJ disc will eventually have normal position without dysfunction of TMJ.

\section{Subgroup Analysis}

Demographic data were obtained, the included researches were mainly divided into 5 subgroups to find out the resource of heterogeneity according to followup year(over or under 1 year), treatment time(over or under 0.5 year), gender ratio(M/F>1, M/F<1 or $M / F \approx 1$ ), total amount of advancement(less or more than $6 \mathrm{~mm}$ ) and publish year(before or after 2010), the result of subgroup analysis was performed in Fig 6 . The result suggested that subgroup 5 (publish year) had little influence on the generation of the heterogeneity. On the contrary, after subgroup analysis, $I^{2}$ in subgroup $1-4$ had decreased to $0 \%$, which illustrated that these factors (gender ratio, follow-up year, treatment time and total amount of advancement)could be regarded as the chief resources of heterogeneity in this study. Further demonstration would be required in discussion.

\section{Discussion}

\section{Summary of evidence}

For this systematic review and meta-analysis, we evaluated the correlation between TMD and fuctional mandibular advancement. Following thorough database searches, it was observed that avaliable researches were rare. 13 literature were included in this systematic review, the quality of selected studies were able to answer this clinical question submitted in this systematic review. According to the criteria of grading evidence given by Cochrane Handbook, our study included 8 randomized clinical trails and 5 systematic reviews. According to meta-analysis, our study indicated that functional mandibular advancement would not cause TMD (P囚0.05).

Most of researches showed that after treatment, position of the condyle was more forward and glenoid fossa also remodelled, even in the patients who have anterior disc displacement with reduction[27], treatment-induced deterioration was not found in the disc-condyle relationship compared with pre-treatment, while the relationship was improved in some cases. The research published by Payam Owtad et al.[28] found that mandibular advancement can increase FGF8 factor in the TMJ area, which can promote adaptive remodeling of the TMJ disc, but it will cost a relatively long time. Published researches had also reported some biomedical effects of functional mandibular advancement devices on the TMJ, the condyle was migrated to a more anterior position, no considerable stress was investigated on the TMJ structure[9, 17, 28, 29], since TMJ discomfort after MADs wearing might be related to muscle dysfunction rather than pressure on TMJ itself[30, 31]. Many researchers also found that adolecence appeared active reconstruction in TMJ area[32, 33]. After categorization of the included case reports according to follw-up period (short-term and long term), five researches set over 1 year follow-up in their experiment, and the outcomes showed that these patients' TMJ morphology were as normal individuals, as well as no adverse effects were observed, also they didn't show more tendency to develop TMD; the other 2 cases reports which observed patients just several months found that compared with initial disc-condyle relationship, no adverse effects were observed, whereas the disc position may improve.

As stated before in subgroup analysis, some other factors besides the intervention method could also affect the result. Four of all included studies used MRI to evaluate the morphology and disc-condyle relationship, many researchers[34,35] found patients who received such treatment were more likely to have their temporomandibular joint disc at a more forward position. Paula Loureiro Cheib et al.'s research[30] indicated that immediately after functional appliance, no significant clockwise mandible rotation was observed, on the contrary, the condyles were displaced anteriorly and inferiorly. The systematic review published by Kurt Popowich[17] also supported for the view above that although few patients had their TMJ disc position changed, such changes might cause TMJ discomfort momentarily, but after a period for TMJ to adapt, subjective symptoms and clinical signs seemed to disappear, and no obvious dysfunction was observed in TMJ. One reason is TMD is a type of self-limiting disease, researches had also already reported that usually after 12 weeks of clinical observation, there was no discomfort complained by patients with disc displacement[36] so follow-up time could be an important reason leading to heterogeneity. And the 
other is no considerable stress was investigated on the TMJ structure when the condyle was migrated to a more anterior position[10, 31, 37], since TMJ discomfort after MADs wearing might be related to muscle dysfunction rather than pressure on TMJ itself[2, 15].

\section{The correlation between gender and TMD}

Gender can also be considered as a major factor which might affect the result. The studies published by Sabine Ruf[38], Niko C. Bock[39], and Ken Hansen[29] all had bias on selecting samples, especially Ken Hansen's study, their samples were all males. As Bueno $\mathrm{CH}$ et al.[40] stated in their systematic review that compared to men, the risk that women developed TMD was two times greater. So did Sójka A et al.'s observational research[41] on medical students in found that about one-third of the students in this study presented symptoms of TMD, and female students showed a higher level of these syptoms. Tae-Yoon Kim et al.[42] gave evidence in their research that there may be physiological and pathological gender differences in TMD. Totally ,there were more males in included samples than females in our study, since it already has evidence that women are more likely to have TMD, different gender ratio in study samples might affect the results a lot.

\section{The correlation between total amount of advancement and TMD}

Furthermore, to assess the relevant influence that total amount of advancement had on TMJs ,we compared patients who recieved over or less than $6 \mathrm{~mm}$ total advancement , and designed a subgroup. It had statistical significance in our reasearch that over $6 \mathrm{~mm}$ advancement would not cause TMD after treatment $(p<0.05)$. Knappe SW[43] and his colleagues compared this two groups in their study, during a long period of follow-up for 2 years, they observed great amount of total mandibular advancement would not make patients have higher risk to rise TMDs.

\section{The correlation between treatment period and having TMJ subjective symptoms}

We also found that treatment time for functional appliance use would affect the outcomes, too. There were more patients who underwent over 0.5 year treatment period complaining about TMJ symptoms than those who underwent treatment period less than 0.5 year. During treatment, patient's mandible was positioned more forward, and the condylar also migrated anteriorly[10]. Stress on the temporomandibular joint structures considerably increased, so it might lead to TMJ symptoms report. As the treatment time prolonged, minor functional disturbances in the masticatory system appeared[6, 44]. But these disturbances were temporary[45], the symptoms would finally disappeared when the remodeling of condylar finished.

\section{The effect existed TMD having on outcomes}

Besides, patients with or without TMD before treatment will also affect the result. Peltola J S[15] took radiographic examination during follow-up time, they found that the condylar findings of patients with existed TMD had remained constant. It suggested that the subjective symptoms and clinical signs seemed to cause the subjects no or only minor problems. Among all the included studies, only studies published by Sabine Ruf et al.[38] and Laura Ivorra-Carbonell et al. [18] concerned about both healthy patients and patients with pre-existing disorders. And they all found that functional mandibular advancement would not have adverse effect on these two kinds of patients. Laura Ivorra-Carbonell[18] summarized in their systematic review that after treatment, position of the condyle was more forward, glenoid fossa also remodeled and the adaption of condyle's morphology was inspected, no any significant adverse effect on the TMJ was observed. Sabine Ruf[38] also pointed out in their study that total disc displacement with reduction or without reduction could not be regarded as contraindications of applying functional mandibular advancement. But the researchers also indicated that for high-risk patients (patients with pathological changes in condyle), the use of such treatment should be of careful attention[6, 46].

\section{Limitations}

Limited RCTs were included in this study, which might lead to an inherent risk of bias. In addition, most articles didn't provide us large samples to examine, and short-time observation may also cause bias. More high-quality studies with low bias are recommended.

\section{Conclusions}

This study formulated a strict inclusion criteria to make the program of gathering and analyzing data more repeatable. The result of this meta-analysis performs that (1) TMJ symptoms may occur during the functional oral appliance wearing, but the symptoms will release or disappear during follow-up period. (2) Less convinced evidence indicate that slightly previous TMD will be improved after treatment. (3) There is TMJ disc anterior displacement observed during treatment, but most of them will return to the normal position later. (4) Moderate evidence support that FMA will not induce or aggravate TMD. But gender, follow-up year, total amount of advancement and treatment period may affect the result to a certain extent, so a more detailed and rigorous experiment should be designed to decrease the bias from gender, follow-up year, total amount of advancement and treatment period.

\section{Declarations}

\section{Acknowledegments}

The authors report no commercial, proprietary, or financial interest in the products or companies described in this article. 


\section{Ethics approval and consent to participate}

Not applicable.

\section{Consent for publication}

Not applicable.

\section{Availability of data and materials}

The results of data extraction in this study are available from the corresponding author on reasonable request.

\section{Competing interests}

The authors declare that they have no competing interests.

\section{Funding}

This work was supported by grants National Natural Science Foundation of China (Nos. 81670969) and The Project of School/Hospital of Stomatology, Lanzhou University囚lzukqky2020-07)

\section{Authors' contributions}

LD and RC conducted the literature search and data extractions, LD performed the statistical analysis and draft the manuscript. LR designed the study and revised the manuscript. All authors read and approved the final version of submission.

\section{Author details}

${ }^{1}$ School of Stomology, Lanzhou University, China.

\section{References}

1. Chen CM, C.M.C.J., Facial profile and frontal changes after bimaxillary surgery in patients with mandibular prognathism. Journal of the Formosan Medical Association, 2018. 7(117): p. 632-639.

2. Jie Lei, A.U.J.Y., Condylar repair and regeneration in adolescentsyoung adults with early-stage degenerative temporomandibular joint disease $A$ randomised controlled study. J Oral Rehabil., 2019(46): p. 704-714.

3. Cheib, P.L., et al., Displacement of the Mandibular Condyles Immediately after Herbst Appliance Insertion - 3D Assessment. Turk J Orthod, 2016. 29(2): p. 31-37.

4. W R Proffit, H.W.F.J., Prevalence of malocclusion and orthodontic treatment need in the United States. Int J Adult Orthodon Orthognath Surg., 1998. 13(2): p. 97-106.

5. Jr. MCNAMARA, J.A., Components of Classânmalocclusion in children 8-10years of age. Angle Orthod, 1981. 51(3): p. 177-202.

6. Hui Xiong, U.H.G.T., The effect of continuous bite jumping withthe Herbst appliance on the masticatorysystem a functional analysis of treatedClass II malocclusions. Angle Orthod., 2004. 1(74): p. 86-92.

7. A. B. M. Rabie, H.X.U.H., Forward mandibular positioning enhances condylar adaptation in adult rats. European Journal of Orthodontics, 2004. Volume 26(Issue 4): p. Page 353-358.

8. L. R. Dermaut, D.C.M.F., Orthopedics in orthodontics: Part I, fiction or realityma review of the literature. American Journal of Orthodontics and Dentofacial Orthopedics, 1996. 110(5): p. 513-519.

9. Lars Bondemark, R.L., Craniomandibular status and function in patients with habitual snoring and obstructive sleep apnoea after nocturnal treatment with a mandibular advancement splint: a two-year follow-up. European Journal of Orthodontics, 2000(22): p. 53-60.

10. Heidsieck DSP, K.J.D.R., Biomechanical effects of a mandibular advancement device on the temporomandibular joint. J Craniomaxillofac Surg, 2018. 2(46): p. 288-292.

11. Tadaharu Kobayashi, N.I.T.K. and C.S. Isao Saito, Progressive condylar resorption after mandibular advancement. British Journal of Oral and Maxillofacial Surgery, 2012(50): p. p176-180.

12. Junho Jung, J.K.J.L., Three-dimensional volumetric analysis of condylar head and glenoid cavity after mandibular advancement. Journal of CranioMaxillo-Facial Surgery, 2018(46): p. 1470-1475.

13. Gero Kinzinger, C.K., Topography and morphology of the mandibular condyle during fixed functional orthopedic treatment -a magnetic resonance imaging study. J Orofac Orthop, 2007. 2(68): p. 124-47.

Page $10 / 14$ 
14. Owen, A.R., Unexpected TMJ responses to functional jaw orthopedic therapy. Am J Orthod Dentofacial Orthop, 1988. 94(4): p. 338-49.

15. Peltola, J.S., M. Kononen and M. Nystrom, A follow-up study of radiographic findings in the mandibular condyles of orthodontically treated patients and associations with TMD. J Dent Res, 1995. 74(9): p. 1571-6.

16. Perry, H.T., Adolescent temporomandibular dysfunction. American Journal of Orthodontics, 1973. 63(5): p. 517-525.

17. Kurt Popowich, B.N.P.W., Effect of Herbst treatment on temporomandibular joint morphology: A systematic literature review. American Journal of Orthodontics and Dentofacial Orthopedics, 2003. 123(4).

18. Laura Ivorra-Carbonell, J.M.J.A., Impact of functional mandibular advancement appliances on the temporomandibular joint - a systematic review. Med Oral Patol Oral Cir Bucal., 2016. 21(5).

19. Julian P. T. Higgins, J.T.J.C., Cochrane Handbook for Systematic Reviews of Interventions, Second Edition. The Cochrane Collaboration, 2019.

20. Alessandro Liberati, D.G.A.J., The PRISMA statement for reporting systematic reviews and meta-analyses of studies that evaluate health care interventions explanation and elaboration. Annals of Internal Medicine, 2009(151): p. w65-w94.

21. Higgins JP, A.D.G.P., The Cochrane Collaboration's tool for assessing risk of bias in randomised trials. BMJ., 2011(343): p. d5928.

22. Popowich K, N.B.M.P., Effect of Herbst treatment on temporomandibular joint morphology a systematic literature review. American Journal of Orthodontics \& Dentofacial Orthopedics, 2003. 4(123).

23. Ivorra-Carbonell L, M.J.A.J., Impact of functional mandibular advancement appliances on the temporomandibular joint - a systematic review. Med Oral Patol Oral Cir Bucal., 2016. 5(21): p. e565-72.

24. Santana LG, A.K.F.C., Incremental or maximal mandibular advancement in the treatment of class II malocclusion through functional appliances: A systematic review with meta-analysis. Orthod Craniofac Res., 2020. 4(23): p. 371-384.

25. Kyburz KS, E.T.P.S., What effect does functional appliance treatment have on the temporomandibular joint? A systematic review with meta-analysis. Prog Orthod., 2019. 1(20).

26. Xinqi H, X.C.J.L., Meta-analysis of the condylar position changes produced by functional appliances in class â区 malocclusion. West China Journal of Stomatology, 2016. 6(34): p. 589-593.

27. Susan Armijo-Olivo, L.P.V.S., The effectiveness of manual therapy and therapeutic exercise for temporomandibular disorders a systematic review and meta-analysis. Phys Ther., 2016. 96(1): p. 9-25.

28. Owtad Payam, P.Z.S.G., A histochemical study on condylar cartilage and glenoid fossa during mandibular advancement. Angle Orthod., 2011. 2(81): p. 207-6.

29. Ken Hansen, H.P.A.P., Long-term effects of the Herbst appliance on the craniomandibular system with special reference to the TMJ. European Journal of Orthodontics, 1990. 12: p. 244-253.

30. Paula Loureiro Cheib Vilefort, L.O.F.H., Condyle-glenoid fossa relationship after Herbst appliance treatment during two stages of craniofacial skeletal maturation: A retrospective study. Orthod Craniofac Res, 2019. 22(4): p. 345-353.

31. Näpänkangas R, R.A.S.K., Effect of mandibular advancement device therapy on the signs and symptoms of temporomandibular disorders. J Oral Maxillofac Res., 2013. 4(3): p. e5.

32. Xin, Y., et al., MRI analysis of the effect on mandibular retrusion with anterior disc displacement treated by using Herbst appliance. Chin J Stomatol, 2017. 52(3): p. 171-175.

33. Jia Wen-min, Q.M.H.G., Effect of Twin-block appliance on condylar process location during mandible forward positioning: Quantitative measurements. Journal of Clinical Rehabilitative Tissue Engneering Research, 2009. 13(52).

34. Gero Kinzinger, N.G.A.R., Disc-condyle Relationships during Class II Treatment with the Functional Mandibular Advancer (FMA). Journal of Orofacial Orthopedics, 2006(5).

35. Gero Kinzinger, N.G.A.R., Disc-condyle Relationships during Class II Treatment with the Functional Mandibular Advancer (FMA) Diskokondyläre Relationen bei der Therapie von Distalbisslagen mit dem Functional Mandibular Advancer (FMA. J Orofac Orthop., 2006. 67(5): p. 356-75.

36. Miernik M, W.W., The Basic Conservative Treatment of Temporomandibular Joint Anterior Disc Displacement Without Reduction-Review. Adv Clin Exp Med., 2015. 4(24): p. 731-5.

37. Kinzinger GSM, L.J.B.D., Are morphologic and topographic alterations of the mandibular fossa after fixed functional treatment detectable on tomograms? Visual classification and morphometric analysis. J Orofac Orthop., 2018. 6(79): p. 427-439.

38. Sabine Ruf, H.P., Does Bite-Jumping Damage the TMJ A Prospective Longitudinal Clinical and MRI Study of Herbst Patients. Angle Orthodontist, 2000. 70(3): p. 183-199.

39. Niko C. Bock, S.R., Long-term ( $\geq 15$ years) effects of Class II treatment a longitudinal and cross-sectional study on signs and symptoms of temporomandibular disorders. European Journal of Orthodontics, 2018: p. 1-8.

40. Bueno CH, P.D.P.M., Gender differences in temporomandibular disorders in adult populational studies A systematic review and meta-analysis. Journal of Oral Rehabilitation, 2018. 45(9): p. 720-729.

41. Anna Sójka, B.S.M.R., Is there a relationship between psychological factors and TMD? Brain and Behavior., 2019 (9): p. e01360.

42. Tae-Yoon Kim, J.S.J.L., Gender Difference in Associations between Chronic Temporomandibular Disorders and General Quality of Life in Koreans A CrossSectional Study. PLoS One, 2015.

43. KNAPPE, S.W., et al., Long-term side effects on the temporomandibular joints and oro-facial function in patients with obstructive sleep apnoea treated with a mandibular advancement device. Journal of Oral Rehabilitation, 2017(44): p. p354-362.

Page 11/14 
44. Valladares-Neto, J., et al., TMJ response to mandibular advancement surgery: an overview of risk factors. J Appl Oral Sci, 2014. 22(1): p. 2-14.

45. Hui-Min Chen, M.L.A.U., Physiological effects of anterior repositioning splint on temporomandibular joint disc displacement a quantitative analysis. J Oral Rehabil., 2017. 44(9): p. 664-672.

46. Cristina V. Perez, R.D.L.J., The incidence and prevalence of temporomandibular disorders and posterior open bite in patients receiving mandibular advancement device therapy for obstructive sleep apnea. Sleep Breath, 2013(17): p. 323-332.

\section{Figures}

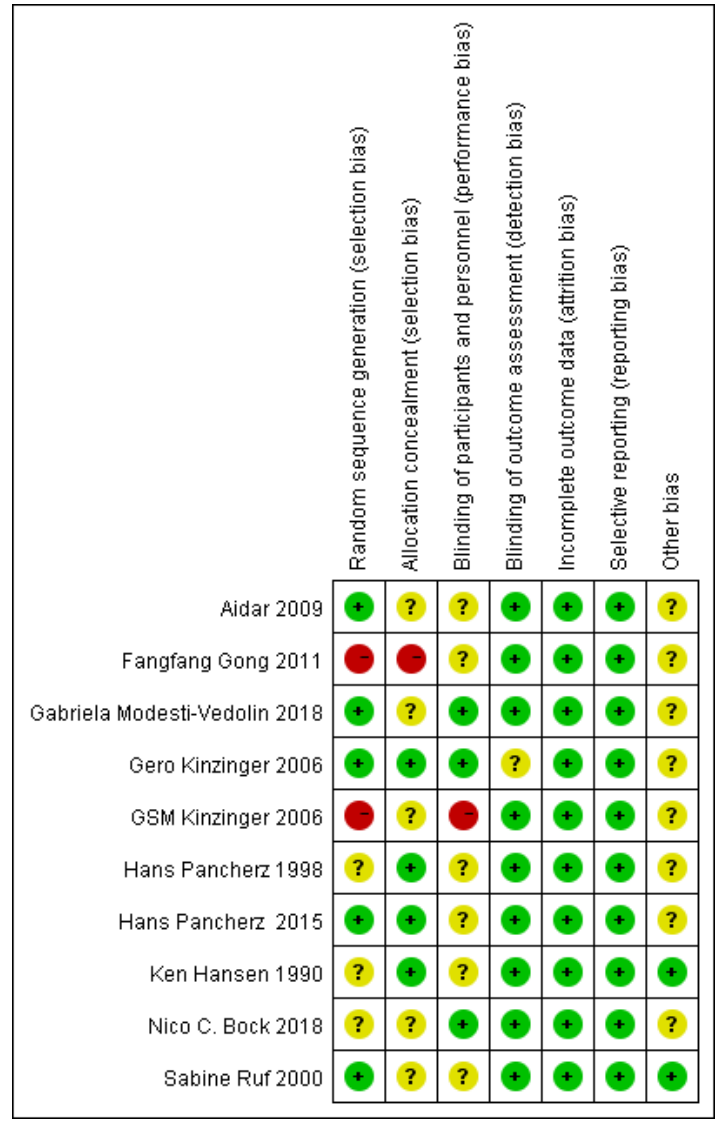

Figure 1

Risk of bias summary

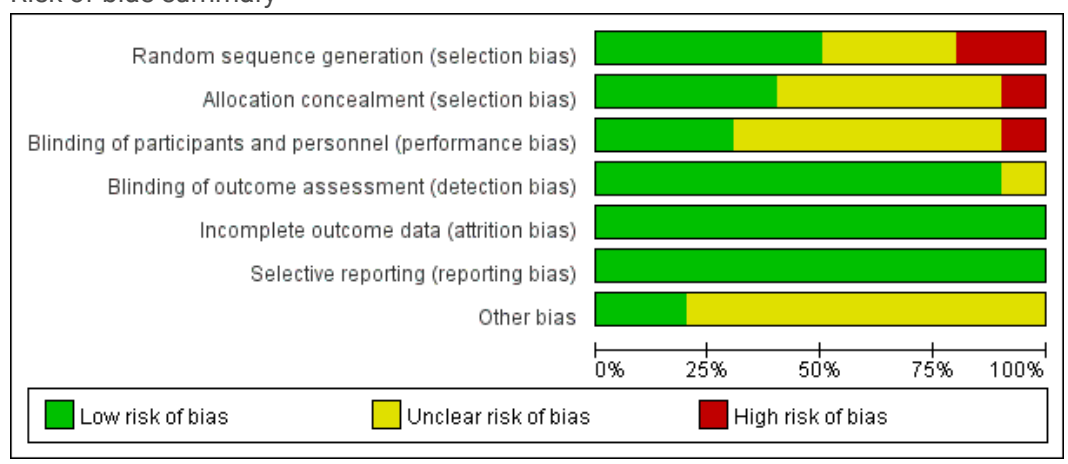

Figure 2

Risk of bias. Review author's judgments about each risk of bias item presented as percentage across all included studies 


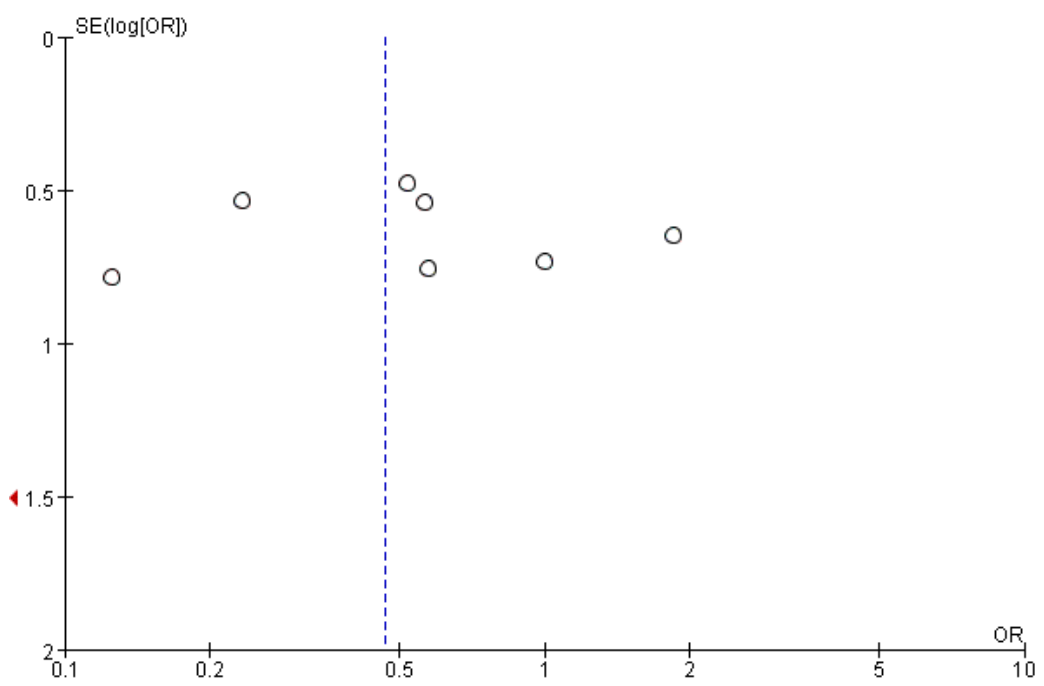

\section{Figure 3}

Funnel plot to display the publication bias

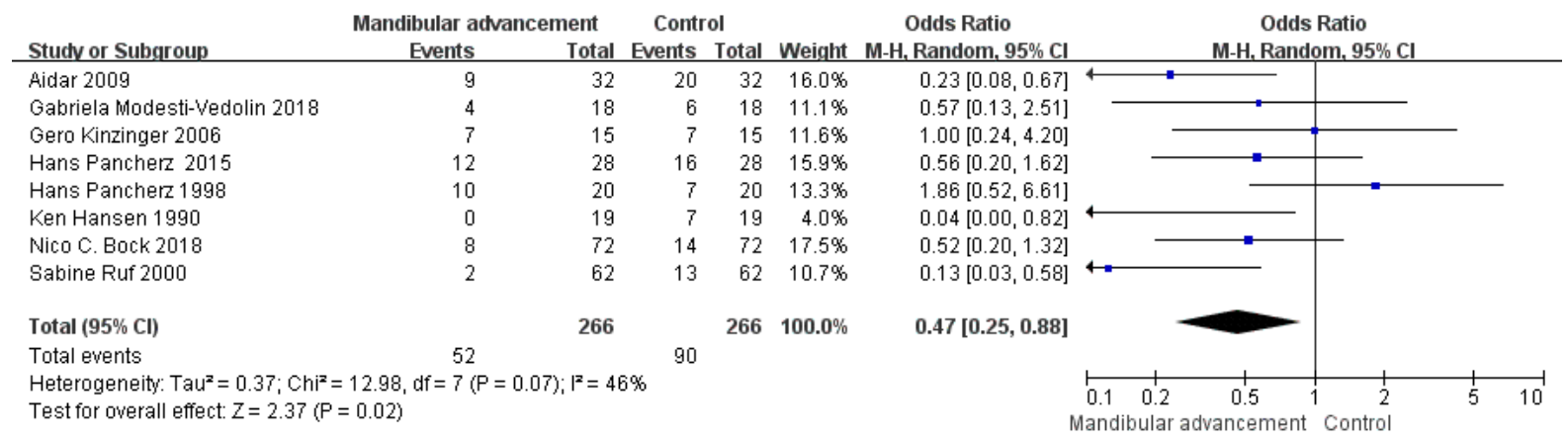

\section{Figure 4}

The comparison between pre and post-treatment(OR)

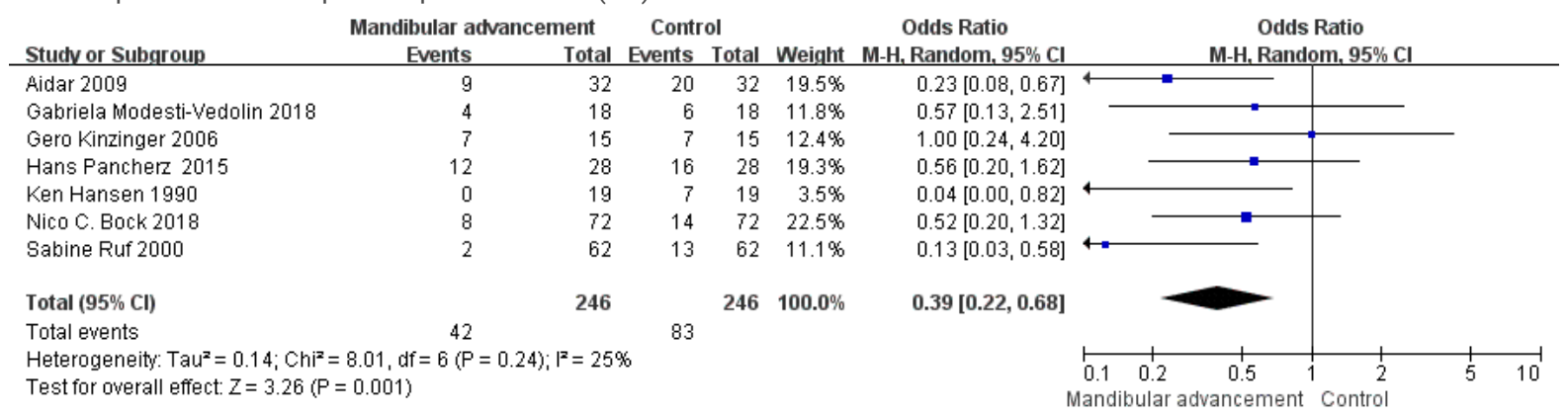

\section{Figure 5}

The result of sensitivity analysis(after removing the study of Hans Pancherz 1998) 


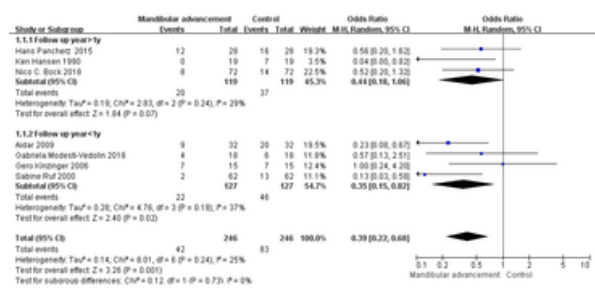

A

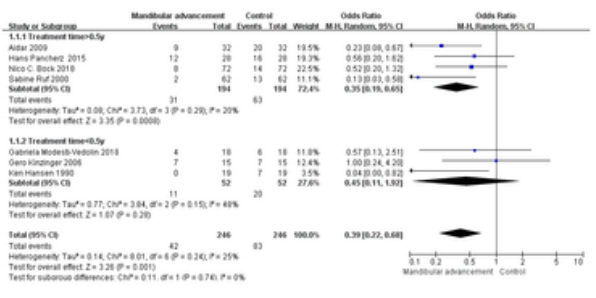

B

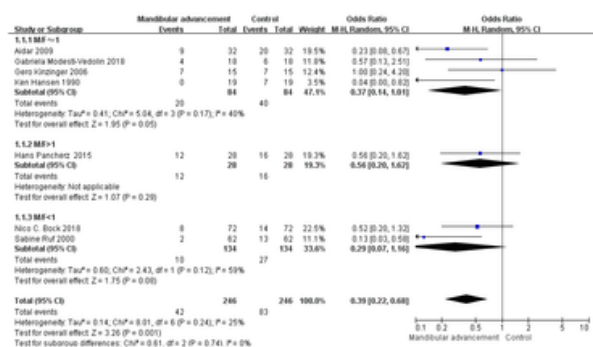

C

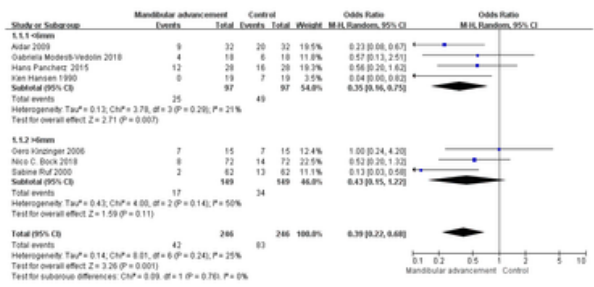

D

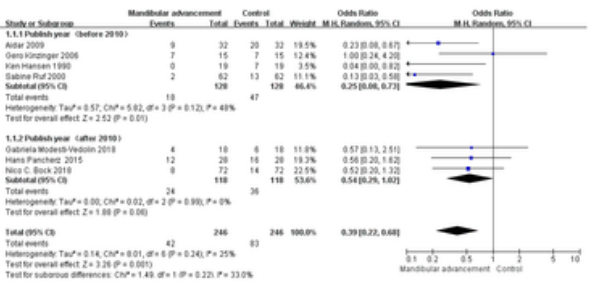

E

\section{Figure 6}

The result of subgroup analysis(A-E)

\section{Supplementary Files}

This is a list of supplementary files associated with this preprint. Click to download.

- SupplementaryMaterial1.docx

- SupplementaryMaterial2.doc 